\title{
Observing wildlife through the eyes of Nils Lindahl Elliot
}

\author{
Nelly Mäekivi, Silver Rattasepp ${ }^{1}$
}

Review of Observing Wildlife in Tropical Forests. 1: A Geosemeiotic Approach by Nils Lindahl Elliot. Bristol: Delome Publications, 2019, 480 pp.

Nils Lindahl Elliot has significantly contributed to semiotic analysis of nature and to the ways in which it is mediated, especially with his transdisciplinary social semeiotic approach that he developed in Mediating Nature (2006). This book propelled his recognition in the field of semiotic studies, especially amongst the ecosemiotic community. In Lindahl Elliot's newest book Observing Wildlife in Tropical Forests. 1: A Geosemeiotic Approach he delves even deeper into transdisciplinary inquiry of observing wildlife, using what he calls a geosemeiotic approach (with the extra " $e$ " serving as a tribute to Peirce). More traditionally, geosemiotics is seen as a research field that studies social meanings of signs, discourses and actions as related to a specific place (Scollon, Scollon 2003). Although both Lindahl Elliot's and Scollon and Scollon's approaches incorporate Peircean semiotics when introducing the nature of signs, and consider the specificity of the place of communication in its widest sense to be of utmost importance, the essences of these approaches could not be further from each other. While geosemiotics turns its attention to visual semiotics, interaction order and semiotics of place, geosemeiotics emphasizes the encounter of dynamical bodies; while geosemiotics is concerned with humans, geosemeiotics stresses the coming together of human and more-than-human bodies which constitute assemblages. These are just some cursory differences between geosemiotics and geosemeiotics; what Lindahl Elliot actually proposes is a new transdisciplinary approach, which encompasses different perspectives (semeiotic, geographic, ecological and socioanthropological) on wildlife observation, forming his multifaceted theory into a single coherent framework.

1 Department of Semiotics, University of Tartu, Jakobi 2, Tartu, 51014, Estonia; e-mails: nelly.maekivi@ut.ee, silver.rattasepp@ut.ee 
Right from the start, Lindahl Elliot warns the reader that the book is of a mixed genre and combines a more traditional research monograph with propaedeutic inquiry. Given the volume of the book ( 480 pages), he manages to uphold both sides, and only seldomly errs on either front. Indeed, as a work whose aim lies in introducing, contextualizing and legitimizing his preferences for the theories of certain authors, Lindahl Elliot dwells thoroughly on minute aspects, and situates these not only within the relevant discipline and its trends, but also in historical and social contexts. He even introduces several theories (e.g. positivism, nominalism, culturalism, etc.) only to refute their applicability to his current endeavour. To make his arguments against the core ideas of some theories even more evident, he has coined several neologisms (e.g. 'retinalism, 'noment', etc.) that emphasize his concerns. Though Lindahl Elliot provides little new information, as is in line with his propaedeutic approach, the forays to aspects that he later excludes from his study serve as scaffolding for theories that he sees as valuable in approaching wildlife observations.

The book is intended for a wide audience, e.g. students, people curious about the complex mechanisms of wildlife observation, or those interested in the basics of philosophical ideas. It is an easy reading and at times often works as an encyclopaedia-like writing that aims at creating a dialogue between the interpretations used (and discarded). Given how many authors and scientific traditions Lindahl Elliot follows, it is understandable that sometimes he offers concise overviews to make complex theories more accessible and selects specific aspects that pertain to his inquiry. Critically-minded readers can turn to the original authors to verify the interpretations he offers, or draw their own conclusions. There is enough information provided to do just that, because Lindahl Elliot takes us through his steps of reasoning and explains why he ends up staying true to some ideas and putting aside others. By offering necessary links to his topic to carry out inquiry from multiple angles and infusing several methods, it truly becomes a transdisciplinary endeavour.

The volume is divided into four parts, and although Lindahl Elliot suggests that the different parts could be read independently from one another, we would still recommend reading the book in the provided order. There is a certain logic behind the composition of the volume, as Lindahl Elliot embeds the knowledge established in each preceding part in the subsequent parts. With every part he progresses towards "linking of the here-and-now of more or less direct perception in a certain context with the there-and-then of social and cultural determinations" (Lindahl Elliot 2019: 17), so as to explicate the difference between (wildlife) perception and observation; every part offers a different set of dimensions to achieve this goal. Throughout Volume 1 Lindahl Elliot also refers to elaborations 
that will be tackled in more detail in the upcoming Volume 2 that will serve as a basis for a genealogic inquiry. Nevertheless, the volume at hand definitely serves as an independent whole, explicating the theoretical background of observing wildlife by tourists.

Part 1 of the volume concentrates on positivist perspectives pertaining to the perception of wildlife. Here, Lindahl Elliot introduces several important historical orientations and authors who are relevant not only to philosophy and wildlife observation but also to semiotics more broadly and to ecosemiotics more specifically. In this part he makes an argument for methodological pluralism by demonstrating that no single method or a way of knowing can provide sufficient, in-depth answers to complex questions. Thus he introduces the reader to the history of positivism (e.g. Comte, the Vienna Circle) and the critique of assumptions present in positivist philosophy (e.g. Kolakowski). The main argument Lindahl Elliot proposes against pure positivism is that epistemological criteria and scientific practice should fundamentally stay the same, no matter which species and its relation to the environment is under scrutiny. However, in line with the multimethod approach, Lindahl Elliot does not dismiss causation - one of the pillars of logical positivism - as entailed in relations between events. Lindahl Elliot sees positivist perspectives being represented in the works of David Marr, James J. Gibson and Edward O. Wilson, and suggests that even though some of their ideas have viable assumptions, they involve crucial drawbacks, being, one way or another, reductive.

The authors are carefully picked for their contributions to studies on perception that could be relevant in the context of wildlife observation. Nevertheless, Lindahl Elliot considers them only to clarify why he will not follow in their footsteps. For starters, Lindahl Elliot provides a brief overview of sociobiology and observes how this pertains to human perception of other animals. He argues that Wilson's biophilia, which indicates an innate and evolutionarily grounded human affinity towards other living beings, has several theoretical and methodological problems (e.g. ambiguity, circumstantial evidence, terminological sloppiness, etc.). The main problem Lindahl Elliot raises is interpreting the regularities of our perception or interpretation of other animals from an adaptationist perspective, and he advocates the inclusion of "social, cultural and indeed ecosystematic contexts" (Lindahl Elliot 2019: 60). While presenting Marr's ideas on computational theory of visual perception, Lindahl Elliot points out a problem arising from viewing vision as a sort of computer-based information processing. Focusing entirely on the nervous system and organs necessary for vision, the process of vision becomes a mechanical encoding that once again "decontextualises perception from social, cultural, and environmental determinations" (Lindahl Elliot 2019: 87). Instead, 
Lindahl Elliot argues that visual perception should be viewed together with the rest of the senses, the body, and the environment with which the given body interacts. Further elaborating on this idea, Lindahl Elliot turns to Gibson, who emphasized, through the concept of affordances, the roles of the environment and the organism in the process of perception. Even though Lindahl Elliot sees Gibson's ecological approach as directly contradicting Marr's 'retinalism', he is concerned about Gibson's pursuit of a radically empiricist approach that ignores the role of representation and memory in perception. Additionally, observation, for Lindahl Elliot, is not a synonym for perception - observation is attentive perception, often accompanied by interpretation and conceptualization.

In the second part of the volume, Lindahl Elliot tackles wildlife observation more thoroughly. Here he also engages directly with semiotic inquiry, which "seeks to elucidate how it is that signs at once constitute, present, and mediate all manner of phenomena" (Lindahl Elliot 2019: 119). Although he introduces Saussurean semiotics, it is only with the objective of letting the reader know that it is not the analytic method he will follow, due to the latter's dyadic approach to the sign, and because Saussurean semiotics dissociates analysis from anthropological interrelations when it comes to wildlife observation. Instead, Lindahl Elliot opts for Peircean semiotics and phenomenology, which he considers much more suitable for analysing objects and events, as these are socially and culturally constructed. It is evident that Lindahl Elliot highly appreciates Peirce's realist perspective on the subject matter of relations between the signs and cosmos, particularly as concerns indexical relations. Peirce's semiotics does not limit semiosis and signs with the human domain, and Lindahl Elliot also sees its appeal in wildlife observation, as Peirce's semiotics enables to "combine indexical and symbolic, 'direct' and associative forms of meaning-making" (Lindahl Elliot 2019: 25).

Lindahl Elliot distinguishes between three semeiotic-phenomenological modalities of observation that are supported by Peirce. These are immediate, dynamical and mediate: immediate modality is predominated by firstness, dynamical modality by secondness and mediate modality by thirdness. In the context of wildlife observation, immediate modality is represented by the possibility of an encounter with wildlife; dynamical modality is brute action and reaction (e.g. getting hit by the snout of the crocodile), and mediate modality is represented by signs (e.g. knowingly trying to stay still till the crocodile decides to leave). The modalities do not always occur in the sequence just described but may vary according to the concrete situation. Though Lindahl Elliot, in line with Peirce, emphasizes the presence of all three modalities in every phenomenon, he also suggests that it is the third modality that is usually prevalent in wildlife observation. Thus, he dedicates Chapter 7 to introducing Peirce's types and classes of 
signs and reflects upon them in the framework of wildlife observation. The end of part two also includes Peirce's biography to help the reader understand why he has not received as much acknowledgement in the wider scientific community as he deserves.

Parts 3 and 4 comprise chapters detailing a myriad of theoretical and conceptual perspectives which supplement and expand Lindahl Elliot's generally Peirceoriented approach, extending the discussion from a more situational analysis to wider and all-encompassing perspectives. Moving from broadly philosophical themes to more ecological ones, we will find a return to James Gibson's ecological perception, biopolitics, actor-network theory, Jakob von Uexküll's umwelt theory and, what seems to be one of Lindahl Elliot's particular favourites, Deleuze and Guattari's assemblage theory. Broadly speaking, the emphasis in this part is on theories and perspectives that help to foreground non-humans, without necessarily reducing them to human representations, to our human access to them. In order to do the foregrounding, Lindahl Elliot first turns his attention to the things that structure, influence and impact on any particular wildlife observation event or situation. A semiotic-phenomenological analysis does not suffice, but rather needs to be expanded by paying attention to the various institutions, representations, discourses, and other influences that precede and lay beyond the specific situation of observation itself, "socio-cultural forces that are quite separate from the observed object, and which go beyond the individual observer" (Lindahl Elliot 2019: 283).

Nevertheless, despite these numerous factors which impact upon any given situation of observation, Lindahl Elliot argues that the "bodies" involved need to be reconceptualized as having agency on their own, an agency which turns any event of observation from an almost mechanically determined moment to a dynamic situation capable of creating its own signs. Here, the target is a kind of top-down culturalism prevalent in the human sciences where individual bodies are thought to be shaped by their culture and society, and their behaviour explained thereby. As the anthropologist Michael Agar (2006: 2) once humorously lamented about such a conception of culture: "The culture concept is a mess in anthropology. Where did such a nice concept go wrong? In the old days, we used it to describe, to explain, and to generalize. A person did something, so it was their culture. Why did they do it? Because it was their culture. Who were they? They were members of that culture. It just does not work like that anymore. It may never have, but we pretended it did". Lindahl Elliot, however, wants to return agency to all the bodies involved in any socio-cultural situation: to humans, to beyond-human creatures, and to things. Moreover, that agency is pre-representational, singular, affective, immanent, and not at all subordinate to being named, categorized, determined, and represented by humans and their culture. 
Finally, Part 4 turns towards ecological and geographical considerations, which in essence means expanding the situational, evental observation further from cultural and social materialities towards even wider biological, ecological and spatial determinants. While this may sound somewhat paradoxical, a central aspect of this is a more "localized" perspective, since cultural and social institutions are often described as if totally present in a given situation, so that the specific bodies, things, their spatial positions and trajectories begin to seem irrelevant. Instead, Lindahl Elliot's focus is on the co-production of signs in and by localized, overlapping, folded, hybrid situations and encounters. For this reason he proposes, by way of a number of theorists, from Uexküll to Deleuze and Haraway, a new conception of 'wild(er)ness', the central issue of which would be "the ontology that one employs to explain the nature of individuals. The conventional ontology starts from essentialised types, and renders any bodies that do not fit with such types as being exceptional; by contrast, the principle of immanence is inclusive in so far as it starts from the 'body itself', which by Deleuzian definition, cannot be an exception" (Lindahl Elliot 2019: 414). Such individual "bodies" are vital entities with their accumulated pasts and experiences, with their intentionality and multiplicity (no body is an island unto itself), all finding themselves as active agents in dynamical situations and encounters. When it comes to wildlife observation, in Lindahl Elliot's own eloquent expression, "there is a kind of coming together in one site, or via one practice, of all the worlds, or at any rate, a 'sample' of such worlds, with important consequences for the nature of the site, and for the experience of the site" (Lindahl Elliot 2019: 417).

A number of concepts and themes echo throughout the book, which can be deemed to be the primary targets of Lindahl Elliot's critique and variants of which he sees as still prevalent not only in understanding wildlife observation more specifically, but more broadly in various theoretical frameworks widely used both today and in the recent past. In Part 1, he presents, drawing on Kolakowski, four assumptions of what he calls a positivist approach to knowledge and ontology: phenomenalism, nominalism, objectivism, and consilience.

Phenomenalism is the claim that there is no difference between essence and phenomena, and thus the only things that can be studied are those manifest in experience. This often leads to the neglect of unobservables such as cultural practices or codes that do not exist anywhere other than in the interpretations of their practitioners. In addition, and somewhat contrary to this, it leads to the foregrounding of representations (phenomena), presenting an asymmetric view of human representations as being more "real" than the actual things they represent, or at least constituting the primary, "accessible" thing. Objectivism describes the well-known naively scientistic claim that value judgements and normative 
statements do not constitute legitimate knowledge. Consilience is what Lindahl Elliot names the standard and equally outmoded belief in the unity of Science and its methods.

Finally, if Observing Wildlife in Tropical Forests has a primary target of criticism that most permeates the entire work, it is what Lindahl Elliot calls nominalism, opposing it to all things realist. Despite this concept being mostly associated with medieval Scholasticism, Lindahl Elliot makes a compelling case that varieties of nominalism - the rejection of the reality of abstractions and/ or universals - is present in a variety of theoretical and philosophical constructs of today. Proceeding primarily from Peirce's pragmatism and mustering forces from a myriad of other theoretical frameworks, Lindahl Elliot makes a compelling case that language is not a unique sign system consisting mostly or entirely of the symbolic, the conventional, and the arbitrary, but rather tends to pick up not only things experiential and embodied, as has long been argued (e.g. by Lakoff, Johnson 1999), but also captures something essential of the things and processes of the world by means of indexical relations. Moreover, with the actuality of signs and their concrete impact on goings-on in the world, what constitutes reality is correspondingly expanded.

All this is very welcome, and taps well into recent trends in continental philosophy of moving away from modes of thinking influenced by post-structuralism and other varieties of representationalism, and towards different forms of realism - either speculative realism, new materialism, object-oriented ontology, or in general what is happening under the wide umbrella of posthumanism/-ities. Whether these align well or poorly with Peircean semiotics and Lindahl Elliot's own thinking is of course an open question, but Observing Wildlife in Tropical Forests makes an important contribution to these various movements.

It is perhaps somewhat unsurprising that there are small mistakes or inaccuracies here and there in a massive work such as this one. Most of these may be caused by simplifications made for the purpose of conveying the basic points of a theory in a straightforward and accessible manner and it does not feel to be particularly relevant to start listing and summarizing them in this review. Nevertheless, to provide an example, we will highlight just one interestingly problematic case which turns out to be not so much a misunderstanding, but rather a generally important point merely aimed at the wrong target. It concerns Bruno Latour and actor-network theory.

Lindahl Elliot claims that "Latour suggests a 'Parliament of Things' that is, by contrast, all about nature-culture hybrids. From this perspective, moderns are, like all other cultural groups, immersed in a world of 'mixtures of nature and culture', and it is these 'mixtures' that need to be explained." (Lindahl Elliot 2019: 347). 
This description of hybrids reverses Latour's thinking. Despite what Latour seems to claim in the quoted passage, hybrids are not "mixtures of nature and culture" for him. Rather, his point is that the procedure of the "modern constitution" is an attempt to pre-emptively purify hybrids, dividing all of their constituents into neatly separate categories of "nature" and "culture". Thus nature-culture dualism is the consequence of this process of purification and not the starting point, whereas it is the hybrids which are the original "natural state" of the human and non-human world around us. Hybrids are empathetically not a result of putting together bits and bobs from nature and culture, but rather the original fodder from which this dualism is derived. Thus, when Lindahl Elliot later criticizes Latour by stating that the " $[\mathrm{u}] \mathrm{se}$ of the term [hybrids] nonetheless runs the risk of reintroducing the very opposition that the researchers attempt to leave behind. Earlier I quoted Latour when he suggested in We Have Never Been Modern the need to consider 'mixtures of nature and culture', and I can think of no better example of the risk I have just referred to" (Lindahl Elliot 2019: 362), he is mostly arguing with his own misreading.

That said, Lindahl Elliot's point is nevertheless well taken. It indeed seems to be the case that the endless exhortations of overcoming this or that binary opposition, culture-nature being the most infamous in this respect, do often end up reinforcing the dualism itself. This is particularly pertinent considering that most of these "overcomings" either amount to nothing but making a decision in favour of one or the other side of the binary (with Lindahl Elliot's main target, positivism, being a prime example of putting all eggs in the "nature" basket, and culturalism doing the opposite), or simply declaring that it is both, interlinked and juxtaposed in different ways (e.g. various uses of terms such as 'naturecultures'). Here Latour is especially relevant, and not only in the form of his actor-network theory, which entirely eschews this pattern of thinking, but perhaps more importantly in his presentation of various modes of existence, of which there are, in Latour's (2013) opinion, at least fifteen.

To conclude our review, we would like to address a question that Lindahl Elliot asks in the preface, namely whether anyone reads books nowadays. We are compelled to answer: yes, yes, we do - we read his book on geosemeiotics of wildlife observation (all 480 pages of it) and we will also read the second volume, especially because, to our knowledge, these volumes are the first detailed theoretical accounts of observing wildlife by tourists. ${ }^{2}$

2 The research supporting this publication has received funding from the Estonian Research Council (PUT1363 "Semiotics of multispecies environments: agencies, meaning making and communication conflicts" and PRG314 "Semiotic fitting as a mechanism of biocultural diversity: instability and sustainability in novel environments"). 


\section{References}

Agar, Michael 2006. Culture: Can you take it anywhere? International Journal of Qualitative Methods 5(2): 2-12.

Lakoff, George; Johnson, Mark 1999. Philosophy in the Flesh: The Embodied Mind and its Challenge to Western Thought. New York: Basic Books.

Latour, Bruno 2013. An Inquiry into Modes of Existence: An Anthropology of the Moderns. Cambridge: Harvard University Press.

Lindahl Elliot, Nils 2006. Mediating Nature. London: Routledge.

Lindahl Elliot, Nils 2019. Observing Wildlife in Tropical Forests. 1: A Geosemeiotic Approach. Bristol: Delome Publications.

Scollon, Ronald; Scollon, Suzanne Wong 2003. Discourses in Place: Language in the Material World. London: Routledge. 